\title{
Contributos da User Experience para a difusão de acervos arquivísticos: uma análise da interação do usuário com a base de dados SIAN
}

\author{
Bianca da Costa Maia Lopes \\ Mestra; Instituto Brasileiro de Informação em Ciência e Tecnologia / Universidade Federal do Rio de \\ Janeiro, Rio de Janeiro, RJ, Brasil; \\ bianca.lopes@gmail.com \\ Eliezer Pires da Silva \\ Doutor; Universidade Federal do Estado do Rio de Janeiro, Rio de Janeiro, RJ, Brasil; \\ eliezerpires@gmail.com
}

\begin{abstract}
Resumo: Ante o despontar de novas tecnologias digitais, significativas mudanças nas dinâmicas de produção, fluxo, disseminação e acesso à informação transformam padrões e comportamentos de seus usuários. Nesse bojo, a potencialidade dos recursos tecnológicos da rede mundial de computadores possibilita a ampliação dos usos sociais dos arquivos, logrando impactos no âmbito da difusão dos acervos arquivísticos. O trabalho aborda o fenômeno de uma nova geração de instrumentos de referência, com base no Sistema de Informações do Arquivo Nacional, principal instrumento de referência disponibilizado pelo Arquivo Nacional brasileiro, empreendendo-se uma investigação por meio da perspectiva de User Experience Design. Parte-se de revisão bibliográfica e, em seguida, promove-se a coleta e a análise de dados, segundo a adaptação de métodos empíricos com normas de usabilidade. A partir dos resultados obtidos, buscou-se compreender a percepção dos usuários sobre a ferramenta e identificar seus recursos e funcionalidades passíveis de alterações, a fim de facilitar e aperfeiçoar a experiência dos usuários. Os resultados apontam para uma insuficiência dos instrumentos de referência online das instituições arquivísticas, para atingir um maior público, em que pesem os critérios de inteligibilidade, operacionalidade e satisfação dos usuários.
\end{abstract}

Palavras-chave: Instrumentos de referência. User Experience. Difusão de arquivos.

\section{Introdução}

No contexto das novas tecnologias digitais de informação e comunicação, significativas mudanças nas dinâmicas de produção, fluxo, disseminação e acesso à informação perpassam o fenômeno arquivístico, alterando padrões e comportamentos de seus usuários. Nesse cenário, uma gama de recursos 
técnicos, disponibilizados pela internet, afeta os meios de recuperação e acesso às informações em rede, estimulando novas possibilidades de difusão dos arquivos.

No âmbito do processo de descrição arquivística, a emergência de uma nova geração de instrumentos de referência online envolve aspectos tanto de ordem tecnológica, quanto de ordem comunicacional, incutindo um potencial de ampliação do uso social dos acervos de instituições arquivísticas. É permeada, assim, por múltiplos e fecundos campos do saber. Considerando a relação de interação entre usuários e instituições arquivísticas, a interlocução entre a Arquivologia e as áreas afetas ao User Experience (UX) Design, tal qual o Design de Interação e a Arquitetura da Informação, oportuniza contribuições tanto teóricas, quanto práticas ao campo dos arquivos.

Nesse sentido, investiga-se a experiência de uso do Sistema de Informações do Arquivo Nacional (SIAN) - principal base de dados do Arquivo Nacional brasileiro - tendo em vista a importância da interface usuário-sistema para a difusão arquivística do acervo custodiado por esta instituição. Especificamente, buscou-se qualificar o comportamento do usuário na utilização dessa ferramenta, explorando-se o design da interação virtual entre ambos. Além disso, é verificado se o referido instrumento fornece ao usuário o apoio necessário para ampará-lo durante a sua experiência de pesquisa aos acervos arquivísticos. Para tanto, parte-se de revisão bibliográfica, seguida pela coleta e análise dos dados obtidos.

Sem embargo, objetiva-se averiguar em que medida a navegabilidade pelos instrumentos de referência online atende ao propósito de difusão dos acervos arquivísticos à sociedade, efetivamente, contemplando sua compreensão esclarecida como um elemento vital para o acesso.

\section{Descrição arquivística: processo ou produto?}

Em meio a diversos sentidos atribuídos à descrição arquivística, destaca-se a sua manifestação como uma atividade intelectual que visa refletir a utilização de processos e métodos do campo, a fim de representar as informações contidas nos acervos arquivísticos, evidenciando seu conteúdo e contexto. Nesta acepção, a 
descrição é, também, compreendida como uma forma de representação dos arquivos, tal qual pensada pela norte-americana Elizabeth Yakel:

O termo "representação arquivística" capta, mais precisamente, os papeis do arquivista em reordenar, interpretar, criar substitutos e desenhar arquiteturas para sistemas de representação que contenham esses substitutos para suprir ou representar os próprios materiais arquivísticos. (YAKEL, 2003, p. 2, tradução nossa).

Recorrendo à definição do Dicionário Brasileiro de Terminologia Arquivística ${ }^{1}$, o termo descrição consiste no "[...] conjunto de procedimentos que leva em conta os elementos formais e de conteúdo dos documentos para elaboração de instrumentos de pesquisa." (BRASIL, 2005, p. 67). Embora pertinente, tal definição acomoda um aspecto redutor quando, por vezes, a descrição arquivística é associada apenas à produção dos instrumentos de pesquisa, preterindo-se outros produtos também derivados do processo descritivo (OLIVEIRA, 2010, p.45). Dessa maneira, Oliveira (2010) situa os instrumentos de pesquisa como produtos correspondentes apenas a uma parte desse processo, salientando que não contemplariam todo o conhecimento produzido pelo arquivista sobre o acervo. Uma dissociação entre ambos os conceitos também é percebida por Llanes Padrón (2016), similarmente, no âmbito da emergência de novas tecnologias na contemporaneidade:

A evolução tecnológica alcançada nas últimas décadas do século XX permitiu dissociar o conceito de descrição do conceito de instrumento de pesquisa. A descrição consiste em elaborar uma representação (atividade) que pode ter diferentes formas de manifestação (instrumentos de consulta); a partir de uma base de dados descritiva é possível obter diferentes formatos de saída (várias formas de exibição na tela ou diferentes tipos de impressos). (LLANES PADRÓN, 2016, p. 27, tradução nossa).

Digno de nota é que, de maneira geral, a ausência de consenso quanto a essa questão decorre da forma por que a descrição é considerada pela literatura da área: para alguns autores, um produto; para outros, um processo. Sob a ótica de Geoffrey Yeo $^{2}$ (2016), os debates acerca da descrição arquivística apontam para a sua compreensão tanto como um processo, quanto como um produto. Sob esse prisma, o autor relata que as percepções da comunidade arquivística, sobre 
a descrição, diferem quanto à ênfase atribuída a seus papeis e funções: visões distintas tendem a reforçar aspectos como controle, acesso, autenticidade ou contexto. Cabe ressaltar que não se trata de perspectivas incompatíveis necessariamente, mas sim, complementares.

Para Oliveira (2010), em sua tese de doutorado, apesar da literatura da área identificar como finalidades da descrição, tradicionalmente, o controle e o acesso do acervo, diversos elementos compõem camadas de compreensão para a representação do contexto arquivístico. Isso reforça a cientificidade da descrição dos arquivos e sua abordagem como uma função de pesquisa.

Já no intuito de recompor os aspectos históricos da descrição arquivística, Andrade e Silva (2008) realçam a importância da relação entre o conhecimento do contexto e o resultado dessa atividade, indicando a necessidade desse processo abarcar tanto elementos sobre o contexto de criação, quanto outros, retirados do próprio conjunto documental descrito. O trabalho do arquivista, dessa forma, contemplaria a descrição do conteúdo, da estrutura e do contexto dos documentos, preservando a imparcialidade e a autenticidade do documento de arquivo.

Luciana Duranti, por sua vez, sublinha a relação entre a descrição arquivística e a autenticidade, tratando a primeira como uma comprovação da autenticidade de documentos de um fundo e de todas as suas inter-relações:

[...] o único papel importante que os arquivistas têm em relação à autenticidade é descrever os documentos sob sua custódia em contexto, tornando explícita, estabilizando e perpetuando seus relacionamentos com seus criadores e entre eles [...]. (DURANTI, 2011, p. 78, tradução nossa).

A italiana corrobora, assim, o ponto de vista de Yeo (2016), ao afirmar que os autores que enfatizam o contexto ou a autenticidade da descrição demonstram privilegiar um enfoque sobre a presunção de prova dos documentos e das ações que os produzem.

Depreende-se que cumpriria ao arquivista, ao operacionalizar o processo descritivo, compreender não só o contexto dos documentos de arquivo descritos, bem como a interação entre a unidade de informação arquivística e os seus usuários. Para tanto, ressalta-se a criação e aplicação de normas específicas. 
A partir de um levantamento bibliográfico, Oliveira (2010) aponta as normas de descrição arquivística de maior relevância para a área e destaca respectivamente: o Manual de Arranjo e Descrição de Arquivos (vulgo Manual dos Arquivistas Holandeses), em 1898; Manual of Archival Description (MAD), em 1986, 1989 e 2000; Rules for archival description (RAD), em 2008; $\operatorname{ISAD}(\mathrm{G})$ : Norma geral internacional de descrição arquivística, 2003; e Describing archives: a content standard (DACS), em 2008. No Brasil, o Conselho Nacional de Arquivos (Conarq) foi o responsável pelo desenvolvimento da Norma Brasileira de Descrição Arquivística (NOBRADE), a partir da ISAD(G), publicada pelo Arquivo Nacional brasileiro em 2006.

Cabe ressaltar que, em 2012, o Conselho Internacional de Arquivos (CIA) constituiu um grupo de trabalho (INTERNATIONAL COUNCIL ON ARCHIVES, 2017) com 21 especialistas em descrição arquivística, oriundos de 13 países distintos, visando à promoção de melhores práticas nessa temática. Entre 2012 e 2016, o grupo buscou desenvolver um padrão descritivo para conciliar, integrar e construir um modelo a partir das quatro normas de descrição - ISAD $(\mathrm{G})$, ISAAR(CPF), ISDF e ISDIAH -, intitulado "Records in Context" (RiC). Ainda em 2016, na forma de rascunho, o modelo conceitual proposto foi submetido à comunidade arquivística para consulta pública, tendo recebido contundentes críticas pelo InterPARES Trust ${ }^{3}$.

Em relação à variedade das críticas que lhe foram endereçadas, importa aqui apresentar uma delas, referente ao foco sobre o papel dos usuários na proposição dessa modelagem:

O papel dos usuários tem sido cada vez mais um tópico de investigação na literatura científica desses últimos anos. Novas tecnologias oferecem novas e inimagináveis possibilidades de interação com instrumentos de pesquisa, sugerindo, por um lado, a necessidade de reconsiderar e redefinir o papel de instrumentos de pesquisa e, por outro; o papel dos usuários. Os usuários devem ser uma preocupação primária de qualquer projeto que trate de descrição. Este foco nos usuários deve ser preliminar para qualquer definição de elementos de descrição. Sem uma análise minuciosa e compreensão do público-alvo - isto é, a natureza e as características do público - o modelo seria, inevitavelmente, impreciso, se não completamente errado. (INTERPARES TRUST, 2016, p. 7, tradução nossa). 
$\mathrm{Na}$ medida em que os usuários dos arquivos relacionam-se com os acervos descritos na etapa de difusão, julga-se imperativo incluir sua perspectiva em debates sobre a descrição arquivística e suas normas. Do mesmo modo, é oportuno compreender a conjuntura tecnológica que perpassa as relações entre esses usuários ao aceder às informações contidas nos acervos arquivísticos.

Sobretudo, é essencial não perder de vista os limites discursivos de construção dos modelos para a descrição arquivística. Como sinaliza MacNeil (2005), a representação arquivística é seletiva e incapaz de envolver a totalidade do objeto que pretende descrever. Ou, ainda, segundo Foucault, "[...] é óbvio que o arquivo de uma sociedade, de uma cultura, ou de uma civilização não pode ser descrito de maneira exaustiva [...] O arquivo não pode ser descrito em sua totalidade." (FOUCAULT, 2010, p. 148). Nesse sentido, reitera-se que o processo modelizador dessa atividade não deve esquecer as mudanças tecnológicas e os seus impactos na produção de instrumentos de referência, tampouco o peso da atuação do usuário nessa interação.

Retomando a definição mencionada inicialmente por Yakel (2003), a autora aponta que "[...] o próprio ato de representação arquivística, projetado para solicitar e fornecer acesso a acervos através de instrumentos de pesquisa, também pode criar barreiras para o uso.” (YAKEL, 2003, p. 2, tradução nossa). Nesse sentido, consiste em condição essencial que os pesquisadores conheçam e compreendam os esquemas, códigos e linguagens que envolvem os sistemas implícitos de privilegiar, classificar e selecionar. Ainda que regidos por normas, eles remetem a um reconhecido grau de subjetividade. Segundo Yeo (2016),

[...] os arquivistas estão cada vez mais convencidos de que a representação nunca é perfeita, de que concessões precisam ser feitas, de que as normas não são universais, mas produtos localizados de sociedades específicas [...]. Mas já que o trabalho descritivo é necessariamente seletivo, os arquivistas também tomam decisões conscientes sobre o que incluir em suas descrições, o que enfatizar e o que ignorar, e essas decisões inevitavelmente privilegiam alguns aspectos em detrimento de outros. (YEO, 2016, p. 149).

No escopo desta investigação, destaca-se a relevância do papel da descrição dos arquivos, com ênfase sobre o acesso, uma vez que essa função 
entrelaça-se com a participação dos usuários e suas demandas por informações, sendo fundamental para a difusão do conhecimento sobre os arquivos. Sem embargo, entende-se que a descrição arquivística comporta um processo e também os seus respectivos produtos, dentre os quais se incluem os instrumentos de referência.

\section{Web 2.0 e UX Design: caminhos para a difusão dos acervos arquivísticos}

Nas últimas décadas, o advento da tecnologia da informação, no bojo de um novo paradigma, é concebido como a "[...] transferência de uma tecnologia baseada, principalmente, em insumos baratos de energia, para outra que se baseia, predominantemente, em insumos baratos de informação, derivados do avanço da tecnologia em microeletrônica e telecomunicações.” (FREEMAN, 1988, p. 10, tradução nossa) ${ }^{4}$. Ao passo que as transformações tecnológicas interagem com a economia e a sociedade, demarcam mudanças sociais que arquitetam a chamada sociedade da informação. Nesse sentido, para além de uma sociedade informacional, o paradigma da tecnologia da informação provocou uma transformação social por meio de seu uso conformando uma sociedade em rede.

No contexto arquivístico, a disponibilidade de novos recursos informacionais ampliou os horizontes de busca e recuperação da informação e estremeceu a tradicional relação entre usuário e informação. Os usuários dos arquivos, antes agentes passivos na comunicação com as instituições arquivísticas, adquirem outro tipo de postura, figurando tanto como produtores, quanto receptores da informação, conforme as suas necessidades específicas.

Os efeitos da rede mundial de computadores atravessam o comportamento desses usuários ao propiciarem, também, maior visibilidade institucional aos arquivos, revestindo as instituições arquivísticas de maior quantidade de usuários (MARIZ, 2012). Considerando que, além do aspecto quantitativo, a qualidade da relação entre esses atores é vital para o êxito da difusão dos acervos arquivísticos, duas direções de discussão convergem para os propósitos desta investigação: a potencialidade do uso de recursos interativos 
oferecidos pela Web 2.0 e o aporte teórico da User Experience Design ${ }^{5}$, doravante UX, no cenário arquivístico.

A evolução tecnológica da web, da década de 1990 à atualidade, acompanhou as transformações de diferentes formas de disponibilização da informação para o público conectado. Concebido por Berners-Lee (1996), cerca de meio século após os trabalhos de Vannevar Bush sobre o hipertexto, o projeto da World Wide Web mesclou técnicas de recuperação de informação com o hipertexto, a fim de dimensionar a criação de um sistema de informação em nível global (W3C, 1991). A web tradicional ou Web 1.0 consistiu em uma plataforma estática, uma espécie de vitrine informacional. Já na década de 2000, a segunda geração da web popularizou-se como Web 2.0, agregando novos recursos que destacam seu papel como plataforma interativa e sua arquitetura de participação: blogs, redes sociais, wikis, compartilhamento de vídeos online, computação na nuvem, dentre outros (O'REILLY, 2005). Robredo (2010) atenta para o caráter de interoperabilidade dessa geração da web:

A Web 2.0 é vista por alguns como uma segunda geração do desenho e da evolução da Web, que facilita a comunicação e o compartilhamento da informação, a interoperabilidade e a colaboração, com a subsequente proliferação de redes comunitárias e sociais, hospedagem de serviços e aplicações, compartilhamento de vídeos, wikis, blogs e folksonomias. (ROBREDO, 2010, p.16).

Theimer (2011) pontua as mais significativas mudanças entre a primeira e a segunda geração da web: manifestação da rede como plataforma, possibilitando o acesso de dados desde qualquer local provido de conexão à internet; processo de abertura de interfaces técnicas e padrões; websites voltados para a experiência de cada usuário; ampliação do sentido de interatividade, criação de conteúdo pelos usuários; e integração da conexão entre esses. Compreendidas em conjunto, essas transformações alteraram a maneira como as pessoas acessam e interagem com a informação disponibilizada na rede.

Em seguida, a geração da web semântica, como uma proposta de extensão da atual (BERNERS-LEE; LASSILA; HENDLER, 2001), permite a interação entre computadores e pessoas por meio de novas tecnologias e 
linguagens, a partir da representação do conhecimento e da criação de ontologias, apontando para ainda maiores desafios tecnológicos.

Atualmente, parte dos sítios eletrônicos das instituições arquivísticas busca adaptar-se ao formato da Web 2.0, enquanto outra ainda está aprisionada à mentalidade da Web 1.0 (THEIMER, 2009). O cenário brasileiro não é diferente: como apontado por Mariz (2012), tais instituições brasileiras gerenciam tecnologias atuais, com base em parâmetros utilizados por tecnologias anteriores.

No início, a maior parte das informações disponíveis na rede era semelhante aos documentos impressos, textuais. Com o tempo e a adaptação aos novos ambientes, os sites foram se tornando mais complexos. Porém, com poucas exceções, os sites de instituições arquivísticas brasileiras ainda não saíram daquele estágio inicial. (MARIZ, 2012, p.147).

A partir de levantamento realizado por Jardim (1999), observou-se que a porcentagem de websites de instituições arquivísticas públicas brasileiras que apresentavam, na época, instrumento de pesquisa online em base de dados era muito baixa, correspondendo a apenas $15 \%$ do total de sítios institucionais. Desde então, o autor destaca a necessidade de ampliação das informações contidas nos arquivos por meio dos instrumentos de pesquisa, incentivando mecanismos que proporcionem maior interatividade.

No ano subsequente, a elaboração pelo Conarq de diretrizes, recomendando a parametrização de informações dispostas nos websites das instituições arquivísticas brasileiras norteou, em um primeiro momento, a disposição e disseminação da informação sobre os arquivos na rede. Nessa direção, “[...] a maioria dos arquivos percebeu o valor de usar a web para publicar informação sobre si e seus acervos - geralmente, na forma de colocar online instrumentos de pesquisa." (THEIMER, 2011, p. 123, tradução nossa).

O advento da Web 2.0, o entrelaçamento virtual e célere do fluxo informacional, o surgimento da $\operatorname{ISAD}(G)$ e da NOBRADE, a ampliação das políticas de acesso à informação e a tendência de transparência e accountability ${ }^{6}$ na governança pública são fatores que acarretam o encurtamento da distância 
virtual entre o usuário e as instituições arquivísticas. Neste cenário, destaca-se um processo de transição dos instrumentos de pesquisa tradicionais, como o guia e o inventário impressos, por exemplo, para uma nova geração de instrumentos de pesquisa ou de referência ${ }^{7}$ online. Em suma, as recentes tecnologias simplificaram a disseminação da informação descritiva (YEO, 2016). No entanto, será que essa informação tornou-se mais simples para o seu usuário?

Nessa direção, o autor aponta uma lacuna referente à iniciativas para identificar boas práticas em métodos de apresentação e recuperação da informação descrita, desconhecendo-se como a tecnologia afeta, com efeito, as possibilidades de uso das descrições: “[...] na ausência de normas estabelecidas, os usuários, ao consultarem uma gama de recursos on-line, frequentemente precisam aprender uma nova interface e sintaxe de recuperação para cada site que visitam.”(YEO, 2016, p. 152).

Gilliland-Swetland (2001) pontua que a inconsistência na forma de apresentação dos instrumentos de referência os torna incompreensíveis ao usuário leigo:

\begin{abstract}
Em geral, tanto os arquivistas como seus usuários utilizam a mesma versão do instrumento de pesquisa e versões simplificadas ou visualizações alternativas raramente são preparadas para o uso público. Embora a eficácia desta forma em facilitar o uso de materiais de arquivo nunca tenha sido sistematicamente examinada, todas as indicações são de que o instrumento de pesquisa como atualmente concebido desempenha um trabalho bastante fraco em direcionar as necessidades, práticas e comportamentos do usuário não acadêmico. (GILLILAND-SWETLAND, 2001, p. 200, tradução nossa).
\end{abstract}

Desse modo, a multiplicidade de demandas dos usuários dos arquivos enseja uma abordagem mais dinâmica e flexível, salientando uma renovação da maneira pela qual esses interagem com as instituições arquivísticas.

Nesse diapasão, a área de UX caminha ao encontro dessa necessidade, ao passo que é considerada uma recente área do Design e apresenta metodologias específicas para projetos de produtos digitais, com ênfase no design centrado no usuário $^{8}$. De acordo com a definição dada pela norma internacional ISO 9241- 
210 (Human-centred design for interactive systems), o termo user experience corresponde às percepções e respostas dos usuários resultantes do uso e/ou antecipação do uso de um produto, sistema ou serviço.

Essa norma ainda complementa que a UX é consequência, dentre alguns fatores: da performance do sistema; do comportamento interativo; da capacidade assistiva do sistema interativo; e do estado físico e psicológico do usuário, a partir de suas experiências anteriores, preferências, percepções, habilidades e contexto de uso. Diante disso, fica evidente que a área relaciona-se com várias disciplinas para se desenvolver.

Conforme o modelo elaborado por Saffer (2009), as relações interdisciplinares da área de UX são apresentadas em um diagrama (KICKERSTUDIO, 2008), circunscrevendo a navegação, por exemplo, às disciplinas de Arquitetura da Informação, Design Visual e Design de Interação. Yeo (2016) admite que haja potencial para que a navegação torne-se mais sofisticada em ambientes digitais, por meio de "técnicas desconhecidas do mundo do papel". Contudo, reconhece que "[...] os arquivistas ainda não sabem a melhor forma de tornar os instrumentos de pesquisa on-line navegáveis (browsable/navigable)." (YEO, 2016, p. 153).

Em especial, a Arquitetura de Informação (AI) trata de disciplina nuclear do UX Design, oferecendo aportes teóricos relevantes para o campo dos arquivos. Segundo Zwies (2000, p. 11, tradução nossa), é definida como “[...] a arte e a ciência de organizar a informação para ajudar as pessoas a satisfazer suas necessidades de informação de forma efetiva [...] o que implica organizar, navegar, marcar e buscar mecanismos nos sistemas de informação.”. Nessa acepção, a AI relaciona-se mais com a estruturação física das informações, de modo a aperfeiçoar a navegação dos usuários pelos sistemas, do que, propriamente, com o conjunto de elementos que compõem as relações de interação dos usuários, pelo viés da UX.

Em estudo sobre a distinção dos conceitos de user experience e usabilidade, Padovani, Schlemmer e Scariot (2012) realizam ampla revisão de literatura sobre a questão e inferem que, com a evolução do conceito tradicional de usabilidade, este fora encampado pelo termo user experience. Dessa forma, 
ressaltam que os “[...] métodos de avaliação com envolvimento participativo dos usuários também podem ser utilizados para analisar a user experience." (PADOVANI; SCHLEMMER; SCARIOT, 2012, p. 8).

A partir do pressuposto de que o UX Design visa tornar a relação usuário-sistema a mais espontânea e fluida possível, buscando evitar que o sistema torne-se um obstáculo ao usuário, percebe-se que esta área pode oferecer diversas contribuições à Arquivologia. Assim, destaca-se o potencial da UX, no tocante à elaboração de instrumentos arquivísticos de referência online que possam ser intuitivos, inteligíveis e agradáveis ao usuário. Para além de prover acesso, a difusão dos acervos arquivísticos por meio desses instrumentos deve evitar um produto ensimesmado, isto é, concebido de e para especialistas da área arquivística e/ou afins. Sobretudo, difundir os arquivos consiste em reforçar, de modo pragmático, o direito de todos os cidadãos de aceder à informação neles contida.

\section{Análise empírica}

A análise empreendida teve o propósito de avaliar o comportamento do usuário na utilização do SIAN, por meio de suas percepções quanto à experiência de uso, explorando-se o design da interação virtual entre usuário e sistema. Adicionalmente, buscou-se verificar se essa ferramenta fornece ao usuário o apoio necessário, para ampará-lo, durante a sua experiência de pesquisa aos acervos arquivísticos. Não obstante, a análise dos resultados obtidos permitiu a realização de inferências que extrapolam as recomendações de apresentação e uso desse sistema específico para outros instrumentos arquivísticos de referência online.

A escolha do campo empírico da investigação justificou-se diante da relevância tanto da instituição arquivística, quanto da ferramenta analisada em si. Fundado em 1838, ainda sob a denominação de Arquivo Público do Império, o Arquivo Nacional do Brasil conserva mais de 55 quilômetros lineares de acervo documental, segundo seu relatório de gestão de 2015 (BRASIL, 2016). Em relação à ferramenta online, a instituição apresenta o sistema como o 
principal meio de acesso às informações relacionadas ao acervo custodiado pelo Arquivo Nacional, cuja disponibilização remete ao início dos anos 2000. Atualmente, é composto por 899 fundos, 511.344 dossiês e 120.491 itens documentais (BRASIL, 2017). Para acessá-lo, é necessário realizar um cadastro de usuário em seu próprio sítio eletrônico, fornecendo informações sobre identificação, documentação e endereço.

Entre os meses de fevereiro de 2016 a fevereiro de 2017, o sistema teve um total de 343.021 acessos $^{9}$, importando ressaltar que nesse período houve uma mudança de interface, conforme o Gráfico 1. A nova interface entrou no ar no dia 29 de agosto de 2016, passando, a partir daí, a sofrer vários ajustes. Uma estabilização relativa no sistema quanto ao cadastramento de usuários, navegadores, recuperação de dados e etc. foi alcançada em cerca de 45 dias.

Gráfico 1 - Total de acessos ao SIAN entre fevereiro de 2016 a fevereiro de 2017

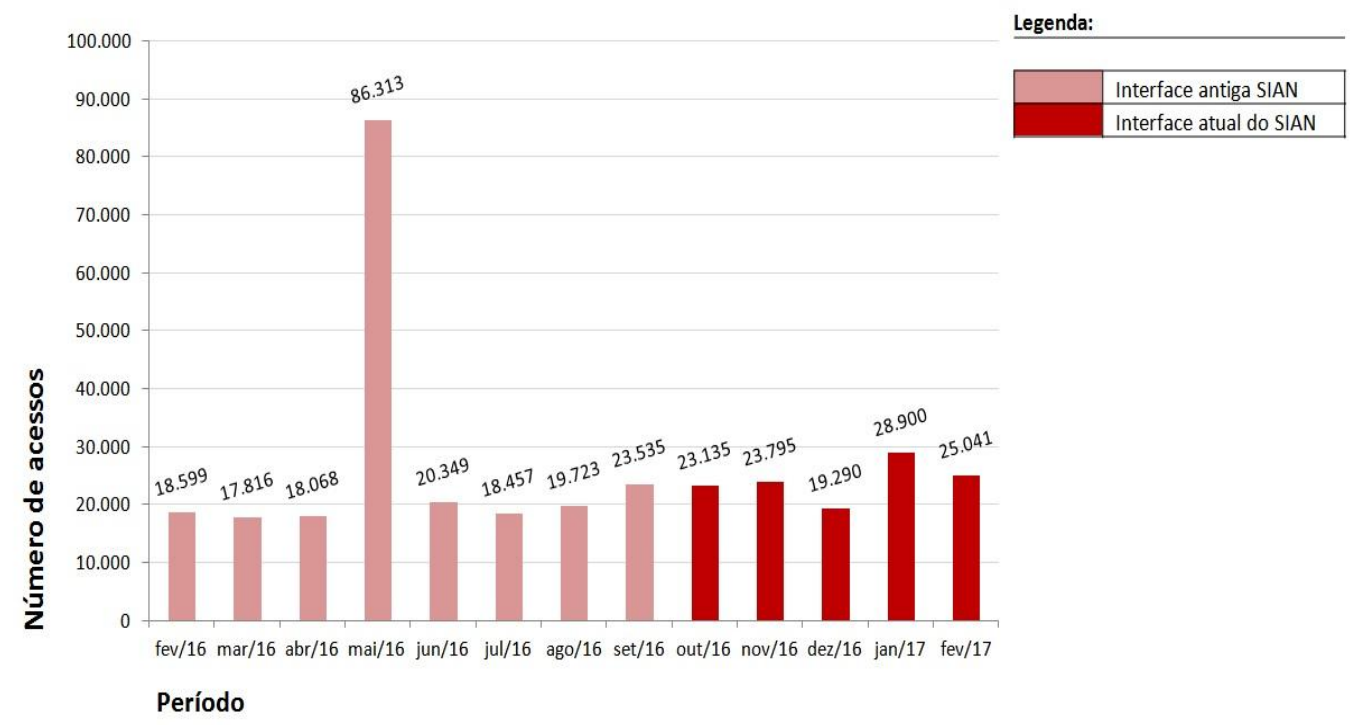

Fonte: Elaborado pelos autores, a partir de dados fornecidos pela Coordenação de Tecnologia da Informação (COTIN/AN).

$\mathrm{Na}$ interface vigente, o SIAN disponibiliza ao público dois módulos: "Fundos e Coleções" e "MAPA", esse último englobando a memória da Administração Pública Federal. Pela aba "Fundos/Coleções", o sistema oferece seis modalidades de pesquisa: livre, avançada, multinível, digital, instrumentos de pesquisa ou notação anterior. Em sua página inicial, há uma breve descrição sobre cada uma dessas opções. 
Para lograr os objetivos desse estudo de natureza exploratória seguiu-se aos seguintes procedimentos teórico-metodológicos: revisão bibliográfica, definição do campo empírico, coleta e análise dos dados. Partiu-se da revisão bibliográfica sobre a descrição arquivística, a evolução da web e estudos sobre User Experience (UX) Design e usabilidade, recorrendo-se a diversos autores das respectivas áreas. Após a delimitação do campo empírico, procedeu-se à coleta de dados, promovendo-se uma verificação empírica da percepção dos usuários selecionados sobre o SIAN, conforme suas experiências de uso. Como instrumento para a realização dessa etapa, optou-se por um questionário do tipo survey, desenvolvido por meio da plataforma online Google Forms.

O questionário desenvolvido dividiu-se em uma apresentação que expõe brevemente o propósito da investigação, a fim de contextualizar o usuário respondente quanto à pesquisa empreendida, além de duas outras partes. Na primeira parte, quatro perguntas fechadas envolvem informações sobre o usuário, como o seu perfil, idade, formação e interesse. Já a segunda parte do questionário consiste em 11 perguntas fechadas e uma aberta, com foco direto sobre as percepções dos respondentes quanto ao uso do SIAN. Dessa forma, em sua totalidade, o questionário é composto por 16 perguntas.

Durante o período de 30 de maio de 2017 a 30 de junho de 2017, foram obtidas 46 respostas completas ao questionário, uma vez que todas as questões eram obrigatórias para a sua conclusão. A pesquisa - sua apresentação e seu respectivo hiperlink para o questionário - foi divulgada em quatro grupos da rede social Facebook que englobam, predominantemente, a temática Arquivologia no contexto brasileiro. Além disso, a pesquisa também foi veiculada na página oficial da mesma rede social do Arquivo Nacional do Brasil. O intuito foi alcançar os usuários de seu próprio instrumento de referência; em uma lista de discussão, por e-mail, de profissionais brasileiros ligados ao ensino da Arquivologia; e em grupos do Facebook de cursos universitários de História, admitindo-se que há um potencial público desta área que utiliza a ferramenta SIAN.

No tocante à sua primeira parte, as respostas sobre o perfil dos respondentes demonstram um predomínio de usuários relacionados ao campo 
teórico ou empírico dos arquivos, totalizando 34 pessoas. Oito são pesquisadores de outras áreas e apenas quatro não se enquadram nas opções anteriores, o que os aproxima da concepção de "cidadão comum". Nesse sentido, nota-se que há uma baixa proporção de respondentes - 8,7\% relacionada a usuários não especializados em pesquisas, de modo geral, ou na matéria arquivística. Presume-se que isso se deve, parcialmente, à dificuldade de aplicação do questionário a um público diversificado, o que demandaria a elaboração de novas estratégias para abarcar essa categoria de usuários.

O quantitativo de respondentes mostrou-se menor na faixa etária entre 39 e 48 anos - seis pessoas - e maior entre 29 a 38 anos - 18 pessoas. O restante das faixas denotou um equilíbrio: 11 respondentes entre 18 e 28 anos e o mesmo número entre igual ou acima de 49 anos.

O nível educacional dos respondentes refletiu diferentes gradações: 22 têm ensino superior completo; sete, doutorado incompleto; seis, superior incompleto; seis, doutorado completo; dois, mestrado completo e mais três, mestrado incompleto.

Em relação aos principais interesses de pesquisa no SIAN, observa-se a predominância da pesquisa acadêmica, apontada por 32 respondentes $(69,6 \%)$, seguida por interesse profissional (56,5\%) e pessoal (32,5\%). A necessidade por alguma informação específica empata com a opção curiosidade, sendo cada uma apontada por $19,6 \%$ dos respondentes.

Já para a segunda parte do questionário, em relação às perguntas fechadas, como caminho de investigação para as percepções dos usuários sobre o SIAN, propôs-se uma adaptação do método empírico de avaliação de usabilidade System Usability Scale (SUS). Criado em 1986, por Brooke (2013), trata-se de uma metodologia de grande repercussão pelo mundo, apresentando um questionário com dez questões capazes de abranger uma visão global do usuário sobre do sistema, em que o respondente assinala a sua resposta de acordo com uma escala Likert.

A partir da adaptação proposta, as respostas obtidas que escapavam aos critérios de avaliação do SUS foram, complementarmente, analisadas sob o prisma de duas normas técnicas relacionadas à usabilidade, a saber, ISO $9126 \mathrm{e}$ 
NBR ISO 9241-11, ou da avaliação heurística de usabilidade proposta por Nielsen (1995).

Segundo Boucinha e Tarouco (2013), a ISO 9126 trata da primeira norma internacional que aborda o conceito de usabilidade, definindo para esta cinco subcaracterísticas: inteligibilidade, apreensibilidade, operacionalidade, atratividade e conformidade. Já a norma NBR ISO 9241-11 apresenta a definição de novos termos, para a compreensão do conceito de usabilidade, como eficácia, eficiência, satisfação, contexto de uso e sistema de trabalho.

Quanto à metodologia de avaliação heurística de usabilidade de Nielsen $(1995)^{10}$, ela consiste em uma técnica preditiva para a avaliação sistemática da interface do usuário no tocante à sua usabilidade. Nesse sentido, o método proposto envolve dez heurísticas - princípios de usabilidade reconhecidos -, porém, a análise empreendida compreendeu apenas duas delas: controle do usuário e ajuda e documentação.

A análise das respostas às questões fechadas buscou destacar a relação entre a metodologia compreendida na pergunta elaborada e o seu núcleo conceitual, conforme o Quadro 1.

Quadro 1 - Relação entre as perguntas fechadas do questionário e a metodologia utilizada

\begin{tabular}{|c|c|c|}
\hline Pergunta do questionário & $\begin{array}{l}\text { Metodologia } \\
\text { correspondente }\end{array}$ & Núcleo conceitual relacionado \\
\hline $\begin{array}{l}\text { A página inicial do SIAN } \\
\text { explica com clareza como } \\
\text { ele pode ser utilizado? }\end{array}$ & ISO 9126 & $\begin{array}{l}\text { Inteligibilidade: facilidade do } \\
\text { usuário em reconhecer a lógica de } \\
\text { funcionamento do produto e sua } \\
\text { aplicação }\end{array}$ \\
\hline $\begin{array}{l}\text { O visual do sistema era } \\
\text { atrativo? }\end{array}$ & ISO 9126 & $\begin{array}{l}\text { Atratividade: evidencia a } \\
\text { satisfação subjetiva do usuário } \\
\text { durante o uso }\end{array}$ \\
\hline \multirow[t]{2}{*}{$\begin{array}{l}\text { O sistema lhe ofereceu } \\
\text { algum recurso de ajuda } \\
\text { durante a pesquisa? }\end{array}$} & $\begin{array}{l}\text { Avaliação heurística } \\
\text { da usabilidade } \\
\text { (Nielsen) }\end{array}$ & Ajuda e documentação \\
\hline & ISO 9126 & $\begin{array}{l}\text { Operacionalidade: medida da } \\
\text { facilidade de operação do sistema }\end{array}$ \\
\hline $\begin{array}{l}\text { Você precisou aprender } \\
\text { novos conhecimentos ou }\end{array}$ & $\begin{array}{l}\text { System Usability } \\
\text { Scale (SUS) }\end{array}$ & $\begin{array}{l}\text { Eu precisei aprender várias coisas } \\
\text { novas antes de conseguir usar o }\end{array}$ \\
\hline
\end{tabular}




\begin{tabular}{|c|c|c|}
\hline \multirow{2}{*}{$\begin{array}{l}\text { habilidades técnicas para } \\
\text { conseguir utilizar esse } \\
\text { sistema? }\end{array}$} & & sistema. \\
\hline & ISO 9126 & $\begin{array}{l}\text { Apreensibilidade: medida da } \\
\text { facilidade de utilização do } \\
\text { software pelo usuário }\end{array}$ \\
\hline $\begin{array}{l}\text { Você precisou ou precisaria } \\
\text { da ajuda de uma pessoa com } \\
\text { conhecimentos técnicos para } \\
\text { utilizar o sistema? }\end{array}$ & $\begin{array}{l}\text { System Usability } \\
\text { Scale (SUS) }\end{array}$ & $\begin{array}{l}\text { Eu acho que precisaria de ajuda de } \\
\text { uma pessoa com conhecimentos } \\
\text { técnicos para usar o sistema. }\end{array}$ \\
\hline $\begin{array}{l}\text { Qual o grau de complexidade } \\
\text { da linguagem utilizada pelo } \\
\text { sistema? }\end{array}$ & $\begin{array}{l}\text { System Usability } \\
\text { Scale (SUS) }\end{array}$ & $\begin{array}{l}\text { Eu acho o sistema } \\
\text { desnecessariamente complexo }\end{array}$ \\
\hline $\begin{array}{l}\text { Qual o grau de dificuldade } \\
\text { para conseguir realizar a sua } \\
\text { pesquisa? }\end{array}$ & $\begin{array}{l}\text { System Usability } \\
\text { Scale (SUS) }\end{array}$ & Eu achei o sistema fácil de usar \\
\hline $\begin{array}{l}\text { Você conseguiu encontrar a } \\
\text { informação que procurava? }\end{array}$ & NBR ISO 9241-11 & $\begin{array}{l}\text { Eficácia: recursos gastos em } \\
\text { relação à acurácia e abrangência } \\
\text { com as quais usuários atingem } \\
\text { objetivos }\end{array}$ \\
\hline $\begin{array}{l}\text { De uma maneira geral, qual } \\
\text { o seu grau de satisfação com } \\
\text { a utilização do sistema? }\end{array}$ & NBR ISO 9241-11 & $\begin{array}{l}\text { Satisfação: ausência do } \\
\text { desconforto e presença de atitudes } \\
\text { positivas para com o uso de um } \\
\text { produto }\end{array}$ \\
\hline $\begin{array}{l}\text { Você voltaria a usar o SIAN } \\
\text { para outras pesquisas? }\end{array}$ & $\begin{array}{l}\text { System Usability } \\
\text { Scale (SUS) }\end{array}$ & $\begin{array}{l}\text { Eu acho que gostaria de usar esse } \\
\text { sistema com frequência }\end{array}$ \\
\hline $\begin{array}{l}\text { Marque todas as suas } \\
\text { impressões ao utilizar o } \\
\text { SIAN: }\end{array}$ & & \\
\hline \multirow[t]{2}{*}{ Satisfação } & NBR ISO 9241-11 & $\begin{array}{l}\text { Satisfação: ausência do } \\
\text { desconforto e presença de atitudes } \\
\text { positivas para com o uso de um } \\
\text { produto }\end{array}$ \\
\hline & ISO 9126 & $\begin{array}{l}\text { Atratividade: evidencia a } \\
\text { satisfação subjetiva do usuário } \\
\text { durante o uso }\end{array}$ \\
\hline Familiaridade & $\begin{array}{l}\text { Avaliação heurística } \\
\text { da usabilidade } \\
\text { (Nielsen) }\end{array}$ & Controle do usuário \\
\hline Facilidade & $\begin{array}{l}\text { System Usability } \\
\text { Scale (SUS) }\end{array}$ & Eu achei o sistema fácil de usar. \\
\hline Esclarecimento & $\begin{array}{l}\text { System Usability } \\
\text { Scale (SUS) }\end{array}$ & $\begin{array}{l}\text { Eu imagino que as pessoas } \\
\text { aprenderão como usar esse sistema } \\
\text { rapidamente }\end{array}$ \\
\hline
\end{tabular}




\begin{tabular}{|l|l|l|}
\hline Frustração & $\begin{array}{l}\text { System Usability } \\
\text { Scale (SUS) }\end{array}$ & $\begin{array}{l}\text { Eu acho que o sistema apresenta } \\
\text { muita inconsistência }\end{array}$ \\
\hline Estranhamento & $\begin{array}{l}\text { System Usability } \\
\text { Scale (SUS) }\end{array}$ & $\begin{array}{l}\text { Eu acho o sistema } \\
\text { desnecessariamente complexo }\end{array}$ \\
\hline Dificuldade & $\begin{array}{l}\text { System Usability } \\
\text { Scale (SUS) }\end{array}$ & $\begin{array}{l}\text { Eu achei o sistema atrapalhado de } \\
\text { usar }\end{array}$ \\
\hline Confusão & $\begin{array}{l}\text { System Usability } \\
\text { Scale (SUS) }\end{array}$ & $\begin{array}{l}\text { Eu achei o sistema atrapalhado de } \\
\text { usar }\end{array}$ \\
\hline
\end{tabular}

Fonte: Elaborado pelos autores.

Para 43,4\% dos respondentes, há pouca clareza quanto às informações dispostas na página inicial do SIAN, e apenas 10,9\% acham que a página utilizase de muita clareza. O visual do sistema é pouco atrativo para $54,4 \%$ dos usuários - apenas um deles avaliou o sistema como muito atrativo. Segundo $65,2 \%$ dos respondentes, o sistema não ofereceu recurso de ajuda durante a pesquisa. Entretanto, 63\% dos usuários alegou que não precisou aprender novos conhecimentos ou habilidades técnicas para o uso do SIAN. Questionadas sobre a necessidade de auxílio de alguém com conhecimentos técnicos para utilizar o sistema, $54,3 \%$ das pessoas responderam positivamente.

Em seguida, a segunda parte do questionário consiste em 11 perguntas fechadas e uma aberta, com foco direto sobre as percepções dos respondentes quanto ao uso do SIAN.

Em relação ao grau de complexidade da linguagem utilizada pelo sistema, $87 \%$ dos respondentes a julgaram como complexa a muito complexa, o que se refletiu na dificuldade para realização da pesquisa: $82,6 \%$ das respostas indicaram esse problema. Apesar da dificuldade, 54,3\% dos usuários afirmaram ter encontrado a informação que desejavam. O grau de satisfação apontado sobre a utilização do sistema pendeu para a insatisfação, visto que $41,3 \%$ dos respondentes mostraram-se pouco satisfeitos, enquanto o mesmo quantitativo percentual não demonstrou satisfação ou insatisfação. Curiosamente, 84,8\% dos usuários responderam que voltariam a utilizar o SIAN para outras pesquisas.

Sobre as impressões ao utilizar o sistema, as três mais indicadas pelos usuários foram, respectivamente: dificuldade $(54,3 \%)$, confusão $(54,3 \%)$ e 
estranhamento (45,7\%). Digno de nota é que, menos apontadas, figuram familiaridade $(10,9 \%)$ e facilidade $(13 \%)$.

Por fim, a última pergunta do questionário proporcionou uma abordagem qualitativa de análise, visto que se tratava de uma questão aberta. Diante do questionamento sobre possíveis melhorias no sistema, para a facilitação da pesquisa, foram selecionadas 12 respostas para análise. Foram descartadas as respostas das pessoas que optaram por não declarar contribuição alguma ou as que, de algum modo, não apresentavam conteúdos relevantes para o escopo da pesquisa. A partir disso, consolidou-se o Quadro 2:

Quadro 2 - Respostas selecionadas para análise sobre a pergunta aberta do questionário

\begin{tabular}{|c|c|}
\hline $\begin{array}{l}\text { Comentários redigidos pelos } \\
\text { respondentes* }\end{array}$ & Análise feita pelos autores \\
\hline $\begin{array}{l}\text { Primeiramente, o acesso ao sistema a partir } \\
\text { da página do arquivo nacional: tive muitas } \\
\text { dificuldades para acessar o SIAN a partir } \\
\text { daquela página. E ainda, a questão da } \\
\text { disponibilização da informação. Eu não sou } \\
\text { arquivista e entendo pouco de descrição } \\
\text { arquivística, procurei informações para uma } \\
\text { disciplina que leciono na Biblioteconomia, } \\
\text { mas encontrei muita dificuldade para } \\
\text { acessar o conteúdo requerido, pelo fato de a } \\
\text { linguagem estar muito específica. }\end{array}$ & $\begin{array}{l}\text { A questão do controle do acesso via cadastro } \\
\text { é uma crítica recorrente. Outro ponto } \\
\text { colocado é a linguagem específica que se } \\
\text { relaciona tanto com o conceito de } \\
\text { operacionalidade quanto inteligibilidade da } \\
\text { norma ISO 9126. Trata-se de um exemplo } \\
\text { que ilustra que o sistema não está centrado } \\
\text { no usuário. }\end{array}$ \\
\hline $\begin{array}{l}\text { Tornar mais simples e mais intuitivo. } \\
\text { Termos e jargões da área arquivística } \\
\text { poderiam ser transformados em palavras de } \\
\text { entendimento comum. }\end{array}$ & $\begin{array}{l}\text { Além da linguagem específica, esse } \\
\text { comentário destaca o fato do sistema ser } \\
\text { desnecessariamente complexo, uma das } \\
\text { perguntas do SUS. }\end{array}$ \\
\hline $\begin{array}{l}\text { Uma linguagem mais acessível às pessoas } \\
\text { não familiarizadas com a dinâmica de busca }\end{array}$ & $\begin{array}{l}\text { A falta de familiaridade com a dinâmica de } \\
\text { busca pode sugerir a necessidade de uma } \\
\text { pessoa com conhecimentos técnicos para } \\
\text { utilizar o sistema (SUS). }\end{array}$ \\
\hline $\begin{array}{l}\text { Uma maior divulgação e um bom passo a } \\
\text { passo }\end{array}$ & $\begin{array}{l}\text { Destaca-se a heurística de usabilidade de } \\
\text { Nielsen "Ajuda e documentação". }\end{array}$ \\
\hline $\begin{array}{l}\text { O sistema deveria ser de mais fácil acesso a } \\
\text { pesquisadores, estudantes, mas } \\
\text { principalmente ao usuário comum. }\end{array}$ & $\begin{array}{l}\text { A facilidade de acesso remete à } \\
\text { apreensibilidade da norma ISO 9126, assim } \\
\text { como à inteligibilidade. }\end{array}$ \\
\hline $\begin{array}{l}\text { Uma interface mais amigável, com } \\
\text { explicações claras para o público leigo e } \\
\text { maior facilidade de entender as } \\
\text { subdivisões, além de uma busca mais fácil. }\end{array}$ & $\begin{array}{l}\text { Uma interface mais amigável requer o } \\
\text { conceito de atratividade, presente na norma } \\
\text { ISO } 9126 \text {. A facilidade da linguagem remete } \\
\text { novamente à apreensibilidade da mesma }\end{array}$ \\
\hline
\end{tabular}




\begin{tabular}{|c|c|}
\hline $\begin{array}{l}\text { a linguagem facilitada seria um grande } \\
\text { diferencial para quem não tem formação em } \\
\text { arquivologia, por exemplo. }\end{array}$ & $\begin{array}{l}\text { norma, enquanto uma busca mais fácil alude } \\
\text { à complexidade de uma das perguntas do } \\
\text { SUS. }\end{array}$ \\
\hline $\begin{array}{l}\text { Uma linguagem mais palatável para o } \\
\text { grande público }\end{array}$ & $\begin{array}{l}\text { Operacionalidade e inteligibilidade da } \\
\text { norma ISO } 9126 .\end{array}$ \\
\hline $\begin{array}{l}\text { Ser mais claro objetivo. Na pesquisa tive } \\
\text { que pedir ajuda a minha orientadora }\end{array}$ & $\begin{array}{l}\text { Efetivamente, houve a ajuda de alguém com } \\
\text { conhecimentos técnicos para auxiliar essa } \\
\text { pessoa (SUS). }\end{array}$ \\
\hline $\begin{array}{l}\text { As informações estarem expostas de forma } \\
\text { mais clara e intuitiva para o usuário }\end{array}$ & $\begin{array}{l}\text { Destaca-se a necessidade de inteligibilidade } \\
\text { do sistema (norma ISO 9126). }\end{array}$ \\
\hline $\begin{array}{l}\text { Melhor interface com o usuário, facilitar as } \\
\text { formas de recuperação da informação, } \\
\text { disposição dos dados mais simples, claras, } \\
\text { diretas. Exclusão de metadados sem } \\
\text { descrição }\end{array}$ & $\begin{array}{l}\text { O comentário mostra a ausência de controle } \\
\text { do usuário (heurística de Nielsen) e a } \\
\text { insuficiência do conceito de atratividade, } \\
\text { presente na norma ISO } 9126 \text {. }\end{array}$ \\
\hline $\begin{array}{l}\text { A linguagem utilizada deveria ser mais } \\
\text { voltada para o usuário, de modo geral. Sou } \\
\text { da área de arquivos e tenho dificuldades em } \\
\text { fazer uma busca simples, mesmo } \\
\text { conhecendo a estrutura multinível da } \\
\text { descrição e os termos técnicos. Imagino que } \\
\text { alguém sem esse conhecimento tenha ainda } \\
\text { mais dificuldades. }\end{array}$ & $\begin{array}{l}\text { Interessante notar que alguém da própria } \\
\text { área tem dificuldades. Isso aponta para o } \\
\text { fato do sistema ser desnecessariamente } \\
\text { complexo e a necessidade de novos } \\
\text { aprendizados antes de conseguir usar o } \\
\text { sistema, duas perguntas do SUS. Além } \\
\text { disso, o comentário remete ao conceito de } \\
\text { operacionalidade (norma ISO 9126). }\end{array}$ \\
\hline $\begin{array}{l}\text { Que fosse um sistema mais claro e voltado } \\
\text { às necessidades do usuário em geral }\end{array}$ & $\begin{array}{l}\text { Implica os conceitos inteligibilidade e } \\
\text { apreensibilidade, ambos referentes à norma } \\
\text { ISO } 9126 .\end{array}$ \\
\hline
\end{tabular}

Fonte: Elaborado pelos autores.

* Os comentários apresentados foram transcritos exatamente como redigidos pelos respondentes.

\section{Considerações finais}

Os dados empíricos coletados apontam para a compreensão da percepção dos usuários sobre o SIAN, a partir de sua experiência de uso, identificando aspectos do sistema passíveis de melhorias e estimulando ações corretivas. O intuito é facilitar e otimizar o acesso e a inteligibilidade desse instrumento, de modo a obter maior grau de satisfação por seus usuários.

Como problemas de usabilidade mais críticos são apontados: a clareza do sistema para os usuários; a necessidade de recursos de ajuda para melhor orientá-los quanto aos mecanismos de busca na base de dados; o uso excessivo de termos técnicos, a ponto de prejudicar o desempenho das buscas realizadas; e a complexidade da linguagem utilizada, de maneira geral. Todos esses pontos 
ratificam as principais impressões dos usuários respondentes sobre o sistema, reforçando a dificuldade, o estranhamento e a frustração quanto ao uso do SIAN.

As respostas à pergunta aberta foram essenciais para verificar a reincidência de comentários predominantemente concentrados sobre a clareza da interface, da linguagem utilizada e da acessibilidade. Muitas dessas respostas mencionam a necessidade de um acesso mais simples para o "usuário comum", "usuário em geral" ou, ainda, "grande público", o que, também, indica múltiplos termos para referenciar o usuário não especializado nos arquivos. É sintomático notar que, embora a maior parte dos respondentes desta pesquisa seja familiarizada com a área de arquivos ou com pesquisas em outras áreas (91,3\%), muito se critica sobre a linguagem utilizada.

Nesse sentido, em que pesem os recursos tecnológicos já utilizados pelo Arquivo Nacional, para a ampliação dos usos e usuários de seus acervos, importa incentivar maior quantidade e diversidade de investigações sobre a relação sistema-usuário. Por ora, há indícios de que o SIAN deva ser revisto, considerando a melhoria dos pontos mais fragilizados; em especial, a inteligibilidade, a operacionalidade e a apreensibilidade do sistema, abarcando a composição plural do público que acessa os arquivos, assim como, aquele que não o visita comumente.

A dimensão social dos arquivos relaciona-se intimamente à capacidade deste se comunicar com a sociedade, o que ultrapassa o mero provimento de acesso à informação contida nos arquivos aos cidadãos. $\mathrm{O}$ potencial comunicacional dos arquivos reside na capacidade deste difundir seus acervos sob a forma de produtos e serviços, de modo a tornar a informação esclarecida para o público que deles faz uso. Nessa direção, o UX Design desponta como um possível caminho para qualificar o acesso aos arquivos, apostando em critérios de usabilidade, a fim de aprimorar recursos e funcionalidades dessa nova geração de instrumentos de referência online. 


\section{Referências}

ANDRADE, Ricardo Sodré; SILVA, Rubens Ribeiro Gonçalves da. Aspectos teóricos e históricos da descrição arquivística e uma nova geração de instrumentos arquivísticos de referência. PontodeAcesso, Salvador, v. 2, n. 3, p. 14-29, 2008.

ANDRADE, Ricardo Sodré; SILVA, Rubens Ribeiro Gonçalves da. Uma nova geração de instrumentos arquivísticos de referência: a publicação dos produtos das descrições arquivísticas em meio eletrônico. In: SIMPÓSIO BAIANO DE ARQUIVOLOGIA, 2., 2009, Salvador. Anais... Salvador: Associação do Arquivistas da Bahia, 2009.

BALMANT, Fabricio Vieira. Terminologia arquivística brasileira: estudo exploratório de publicações e termos. 2016. Trabalho de Conclusão de Curso (Mestrado Profissional em Gestão de Documentos e Arquivos) - Curso de PósGraduação em Gestão de Documentos e Arquivos, Universidade Federal do Estado do Rio de Janeiro, Rio de Janeiro, 2016.

BERNERS-LEE, Tim. WWW: Past, present, and future. Computer, Washington, v. 29, n. 10, p. 69-77, 1996.

BERNERS-LEE, Tim; LASSILA, Ora; HENDLER, James. The semantic web. Scientific American, New York, may 2001.

BOUCINHA, Rafael Marimon; TAROUCO, Liane Margarida Rockenbach. Avaliação de Ambiente Virtual de Aprendizagem com o uso do SUS-System Usability Scale. RENOTE, Porto Alegre, v. 11, n. 3, 2013.

BRASIL. Arquivo Nacional. Dicionário Brasileiro de Terminologia Arquivística. Rio de Janeiro: Arquivo Nacional, 2005.

BRASIL. Arquivo Nacional. Estatística de códigos de referência habilitados. Rio de Janeiro, 2017.

BRASIL. Arquivo Nacional. Relatório de gestão do exercício de 2015. Rio de Janeiro, 2016.

BROOKE, John. SUS: a retrospective. Journal of Usability Studies, Boston, v. 8, n. 2, p. 29-40, 2013.

CASTELLS, Manuel. A sociedade em rede. São Paulo: Paz e Terra, 2003. v. 1.

DURANTI, Luciana. Structural and formal analysis: the contribution of diplomatics to archival appraisal in the digital environment. In: HILL, Jennie (Ed.). The future of archives and recordkeeping: a reader. London: Facet Publishing, 2011. 
FOUCAULT, Michel. A arqueologia do saber. Rio de Janeiro: Forense Universitária, 2010.

FREEMAN, Christopher. Preface to Part II. In: DOSI, Giovanni et al. Technical change and economic theory. London: Pinter, 1988.

GILLILAND-SWETLAND, Anne J. Popularizing the finding aid: exploiting EAD to enhance online discovery and retrieval in archival information systems by diverse user groups. Journal of Internet Cataloging, London, v. 4, n. 3-4, p. 199-225, 2001.

INTERNATIONAL COUNCIL ON ARCHIVES. Expert group on archival description (EGAD). 2017.

InterPARES Trust. Comments on records in context. 2016.

JARDIM, José Maria. O acesso à informação arquivística no Brasil: problemas de acessibilidade e disseminação. In: MESA REDONDA NACIONAL DE ARQUIVOS, 1999, Rio de Janeiro. Caderno de textos... Rio de Janeiro: Arquivo Nacional, 1999.

KICKERSTUDIO. The disciplines of user experience. 2008.

LLANES PADRÓN, Dunia. La descripción archivística en los tiempos posmodernos: conceptos, principios y normas. Marília: Cultura Acadêmica, 2016.

MACNEIL, Heather. Picking our text: archival description, authenticity, and the archivist as editor. The American Archivist, Chicago, v. 68, n. 2, 2005.

MARIZ, Anna Carla Almeida. A informação na internet: arquivos públicos brasileiros. Rio de Janeiro: FGV, 2012.

NIELSEN, Jakob. How to conduct a heuristic evaluation. Fremont: Nielsen Norman Group, 1995.

OLIVEIRA, Lucia Maria Velloso de. Modelagem e status científico na descrição arquivística no campo dos arquivos pessoais. 2010. Tese (Doutorado em Ciências - História Social) - Curso de Pós-Graduação em História Social do Departamento de História da Faculdade de Filosofia, Letras e Ciências Humanas, Universidade de São Paulo, São Paulo, 2010.

O'REILLY, Tim. What is Web 2.0: Design patterns and business models for the next generation of software. Sebastopol: O'Reilly Publishing, 2005.

PADOVANI, Stephania; SCHLEMMER, André; SCARIOT, Cristiele Adriana. Usabilidade \& user experience, usabilidade versus user experience, usabilidade em user experience?: uma discussão teórico-metodológica sobre comunalidades 
e diferenças. In: CONGRESSO INTERNACIONAL DE ERGONOMIA E USABILIDADE DE INTERFACES HUMANO-COMPUTADOR, 12., 2012. Anais... Natal, 2012. p. 1-10.

ROBREDO, Jaime. Ciência da informação e Web semântica: linhas convergentes ou linhas paralelas? In: ROBREDO, Jaime; BRÄSCHER, Marisa. (Orgs.) Passeios pelo bosque da informação: estudos sobre representação e organização da informação e do conhecimento. Brasília: IBICT, 2010.

SAFFER, Dan. The disciplines of user experience. San Francisco: Kicker Studio, 2009.

THEIMER, Kate. Interactivity, flexibility and transparency: social media and Archives 2.0. In: HILL, Jennie (Ed.). The future of archives and ecordkeeping: a reader. London: Facet Publishing, 2011.

THEIMER, Kate. Web 2.0 tools and strategies for archives and local history collections. Chicago: Neal-Schuman Publishers Inc., 2009.

UNIVERSITY COLLEGE LONDON (UCL). Geoffrey Yeo. London, 2017. Geoffrey Yeo Disponível em:

\&lthttp://www.ucl.ac.uk/dis/people/geoffreyyeo\&gt. Acesso em 23 jun. 2017.

W3C. World Wide Web Summary. [S.1.], 1991.

YAKEL, Elizabeth. Archival Representation. Archival Science, Netherlands, v. 3, n. 1, p. 1-25, 2003.

YEO, Geoffrey. Debates em torno da descrição. In. EASTWOOD, T.; MACNEIL, H. (Orgs.). Correntes atuais do pensamento arquivístico. Belo Horizonte: UFMG, 2016.

ZWIES, Richard. Observations on the American society for information science summit 2000 meeting: defining information architecture. Bulletin of the Association for Information Science and Technology, Hoboken, v. 26, n. 5, p. 10-12, 2000.

\section{User Experience contributions for the diffusion of archival collections: an analysis of the interaction between the user and the SIAN database}

Abstract: In front of the emergence of new digital technologies, significant
changes in the dynamics of production, flux, dissemination and access to
information transform patterns and behaviors of its users. In this context, the 
potential of the technological resources of the global computer network allows the expansion of the social uses of the archives, obtaining impacts in the scope of the diffusion of archival collections. The article discusses the phenomenon of a new generation of reference archival instruments, based on the National Archives Information System, the main reference instrument available by the National Archives of Brazil, undertaking an investigation through the perspective of User Experience Design. Based on a literature review, it promotes a data collection and an analysis according to the adaptation of empirical methods and usability norms. The main goal was to understand the users' perception of the tool and to identify its changeable resources and features, in order to facilitate and improve the users' experience. The results point to an insufficiency of the online reference instruments of the archival institutions to reach a wider public, considering the criteria of intelligibility, operability and user satisfaction.

Keywords: Finding aids. User Experience. Archival diffusion.

Recebido: $22 / 07 / 2017$

Aceito: $13 / 11 / 2017$

1 Criado em 2005, o Dicionário Brasileiro de Terminologia Arquivística (DBTA) trata de uma publicação editada e publicada pelo Arquivo Nacional, em versão física e digital. Sua elaboração resultou de um grupo de trabalho da própria instituição, em conjunto com o Conselho Nacional de Arquivos (Conarq) (BALMANT, 2016).

2 Geoffrey Yeo é pesquisador honorário na University College London (UCL), apontando como um de seus interesses de pesquisa a contextualização e a descrição de documentos (UNIVERSITY COLLEGE LONDON, 2017). Disponível em: \&lthttp://www.ucl.ac.uk/dis/people/geoffreyyeo\&gt. Acesso em 23 jun. 2017.

3 Os comentários tecidos pelo à proposta preliminar do modelo "Records in Context" encontram-se disponíveis em InterPARES Trust (2016).

4 Também citado por Manuel Castells (2003, p. 107).

5 Também conhecida como Design de Experiência de Usuário, porém, o uso do termo em inglês é predominante.

6 Contextualiza-se que o termo anglófono accountability, comumente traduzido para a Língua Portuguesa como prestação de contas ou responsabilização social, carrega um sentido ainda mais amplo. Além do ato de prestar contas, consistiria na obrigação em si da Administração Pública de prestar contas.

7 Segundo Andrade e Silva (2009), prioriza-se a terminologia instrumentos arquivísticos de referência ao invés de instrumentos de pesquisa, uma vez que tais ferramentas não comportariam em si mesmas as pesquisas, porém, artefatos referenciais. Por essa razão, optase pelo uso do primeiro termo neste artigo, em detrimento do segundo.

8 Apesar da norma ISO 9241-210 sinalizar a preferência pelo termo human-centred design, na prática, considera-o como sinônimo ao termo user-centred design.

9 A compilação dos dados quantitativos de acessos foi realizada pelo administrador de rede da instituição, observando-se que este número refere-se à "visitas únicas", que identifica o usuário e consolida as páginas acessadas.

${ }^{10}$ Baseado em 294 tipos de erros de usabilidade, o dinamarquês Jakob Nielsen propôs como parâmetro para a avaliação da usabilidade de websites dez itens de análise, as heurísticas. 